\title{
Biomaterials
}

\section{The effect of Gu-Sui-Bu (Drynaria fortunei J. Sm) on bone cell activities}

\author{
Jui-Sheng Sun ${ }^{\mathrm{a}}$, Chun-Yu Lin ${ }^{\mathrm{b}}$, Guo-Chung Dong ${ }^{\mathrm{c}}$, Shiow-Yunn Sheu ${ }^{\mathrm{b}}$, Feng-Huei Lin ${ }^{\mathrm{c}, *}$, \\ Li-Ting Chen ${ }^{\mathrm{a}}$, Yng-Jiin Wang ${ }^{\mathrm{d}}$ \\ ${ }^{a}$ Department of Orthopedic Surgery, National Taiwan University Hospital, Taipei, Taiwan, ROC \\ ${ }^{\mathrm{b}}$ School of Pharmacy, Taipei Medical University, Taipei, Taiwan, ROC \\ ${ }^{\mathrm{c}}$ Graduate Institute of Biomedical Engineering, College of Medicine, National Taiwan University, No. 1, Jen-Ai Road, Taipei, Taiwan, ROC \\ ${ }^{\mathrm{d}}$ Institute of Biomedical Engineering, National Yang-Ming University, Taipei, Taiwan, ROC
}

Received 18 June 2001; accepted 1 January 2002

\begin{abstract}
In the traditional Chinese medicine, Gu-Sui-Bu [Drynaria fortunei (kunze) J. Sm] has been reported as a good enhancer for bone healing. In this experiment, we investigate the biochemical effects of this traditional Chinese medicine on the bone cells culture.

Different concentrations of crude extract of Gu-Sui-Bu were added to rat bone cells culture. The mitochondria activity of the bone cells after exposure was determined by colorimetric assay. Biochemical markers such as alkaline phosphatase (ALP), acid phosphatase $(\mathrm{ACP})$ titer, prostaglandin $\mathrm{E}_{2}\left(\mathrm{PGE}_{2}\right)$ titer and the expression of both osteopontin and osteonectin mRNA were evaluated. The effect on the osteoclasts differentiation was evaluated by tartrate-resistant acid phosphatase (TRAP) stain.

The most effective concentration of Gu-Sui-Bu on bone cells was $1 \mathrm{mg} / \mathrm{ml}$. The addition of $1 \mathrm{mg} / \mathrm{ml} \mathrm{Gu-Sui-Bu}$ to bone cells culture for 7 days can statistically increase the intracellular ALP amount; while the ACP and PGE 2 amount in culture medium were significantly increased. In Northern blot analysis, the expression of both osteopontin and osteonectin mRNA were down-regulated after adding Gu-Sui-Bu into bone cells culture. The formation of multi-nucleated osteoclasts was more active than that of the control group; but no giant osteoclasts formation was observed.

In this study, we demonstrated that Gu-Sui-Bu has potential effects on the bone cells culture. One of the major effects of Gu-Sui$\mathrm{Bu}$ on the bone cells is probably mediated by its effect on the osteclasts activities. Continued and advanced study on the alterations in gene expression of bone cells by Chinese medicines will provide a basis for understanding the observed bone cell responses to various pharmacological interventions. (C) 2002 Elsevier Science Ltd. All rights reserved.
\end{abstract}

Keywords: Osteoblast; Osteoclast; In vitro; Osteopontin; Steonectin; Gu-Sui-Bu

\section{Introduction}

In ancient times, throughout the world, humans used plants as food and medicine. In Europe, chemistry developed rapidly after the influence of Paracelsus. Active principles were isolated from plants, and drugs were prepared in the salt form to be used as medication. In China, several drugs isolated from plants have been prepared in the salt form in recent years, but herbal medication, developed in the ancient tradition, continued to be widely used in Chinese populations [1]. Traditional Chinese medicine is a treasure house, which

\footnotetext{
*Corresponding author. Tel.: + 886-22-312-3456; fax: + 886-22-3912641.

E-mail address: double@ha.mc.ntu.edu.tw (F.-H. Lin).
}

has shown beneficial clinical effects. Reports of efficacy of traditional Chinese medicine are increasing in numbers [2-5]. The increasing popularity of traditional Chinese medicine and/or natural products has also produced fear about their toxicity and uncertainty about their ingredients. In the Western world, medicinal herbs are becoming increasingly popular and important in the public and scientific communities, but they have met with skepticism from much of the medical community. Until the safety, efficacy, mechanism of action, and toxicity determination as well as clinical trials have been scientifically evaluated, many western health care experts are hesitant to embrace their use [6,7].

The traditional Chinese medicines, Gu-Sui-Bu [Drynaria fortunei (kunze) J. Sm] was commonly used to 
manage disorders of orthopedics and had been claimed to have therapeutic effects on bone healing [8]. Specifically, through tissue culture and isotope tracing, it was found that $\mathrm{Gu}-\mathrm{Sui}-\mathrm{Bu}$ injection significantly promoted calcification of the cultivated chick embryo bone primordium, increased ALP activity in the cultivated tissue, and accelerated synthesis of proteoglycan [8]. Later, Liu et al. has shown that Gu-Sui-Bu has an antioxidant effect on rat osteoblasts from hydrogen peroxide-induced death and may promote bone recovery under similar pathologic conditions [9]. Gu-Sui-Bu should be intensively studied for its possible use in bone diseases. In this article, we investigate the biological effects of Gu-Sui-Bu via the in vitro bone cell culture and attempt to elucidate the pharmacological interpretation of their mechanisms of action.

\section{Materials and methods}

\subsection{Preparation of Chinese medicine: $G u-S u i-B u$}

The Chinese medicine, Gu-Sui-Bu [Drynaria fortunei (kunze) J. Sm] used in this study was supplied in dry form by the School of Pharmacy, Taipei Medical University, Taiwan, ROC. Its identification was authenticated by experts in pharmacognosis. The procedures for extraction of these crude drugs were standardized. Briefly, $500 \mathrm{~g}$ of crude drugs were extracted by $70 \%$ acetone for three times, filtered to remove insoluble debris and concentrated in $40^{\circ} \mathrm{C}$ and vacuum evaporation. Then, the mid-products were freeze-dried to get final products used in this experiment.

In the first part of this study, the effects of various concentrations of $\mathrm{Gu}-\mathrm{Sui}-\mathrm{Bu}$ on bone cell activities were evaluated using MTT assay as described below. Seven different concentrations $(10 \mathrm{mg}, 1 \mathrm{mg}, 100 \mu \mathrm{g}, 10 \mu \mathrm{g}$, $1 \mu \mathrm{g}, 100 \mathrm{ng}$, and $10 \mathrm{ng} / \mathrm{ml}$ ) were tested for 1 day, 3 days and 7 days.

\subsection{Osteoblastlosteoclast co-culture (mixed-bone cells culture) and osteoblasts culture}

The rat alveolar mononuclear cells-calvarias osteoblasts co-culture system was the same as previously described [10]. Newborn Wistar rats (3-days old) were obtained from the laboratory center of the Medical College, National Taiwan University. Primary osteoblastic cells were prepared from newborn rat calvarias. For the mixed-bone cells culture, osteoblastic cells $\left(2 \times 10^{3}\right.$ cells/well $)$ and alveolar mononuclear cells $\left(1.5 \times 10^{5}\right.$ cells/well $)$ were co-cultured for 6 days in Dulbecco's modified Eagle's medium containing 10\% fetal calf serum (Gibco BRL, Rockville, MD, USA), $10 \mathrm{~nm} 1 \alpha, 25(\mathrm{OH})_{2} \mathrm{D}_{3}$ in 6 -well plates. Penicillin $\mathrm{G}$ sodium 100 units $/ \mathrm{ml}$ and streptomycin $100 \mathrm{mg} / \mathrm{ml}$ (Gib- co BRL, Rockville, MD, USA) were added. The culture dishes were incubated at $37^{\circ} \mathrm{C}$ in an atmosphere supplemented with $5 \% \mathrm{CO}_{2}$. After 6 days' culture and the differentiated osteoclasts observed, various concentrations of tested Chinese medicines were added for 1 day, 3 or 7 days interval. After various intervals, the media were removed from wells, divided into a section of $500 \mu \mathrm{l}$ with eppendorf, and then deeply frozen in $-80^{\circ} \mathrm{C}$ for further analysis. Equal amount of medium was added after each sampling of tested medium. For the osteoblasts culture, osteoblastic cells $\left(1 \times 10^{5}\right.$ cells/ well) were cultured for 2 days to facilitate their attachment, then a similar preparation and management as that of the mixed-bone cells culture was performed as described above.

\subsection{Colorimetric MTT (Tetrazolium) assay for cell viability [11]}

For the assay, cells were incubated in 96-well plates in the presence of various concentrations of Gu-Sui-Bu. For MTT test of osteoblasts, 6250 cells/well were added, the cells were cultured for 2 days without treatment to facilitate the attachment of cells and then various concentrations of Gu-Sui-Bu were added. On the other hand, 100 osteoblasts cells/well and 7500 mononuclear cells/well were added in the MTT test for the mixedbone cells culture, the bone cells were cultured for 6 days without treatment to facilitate the attachment of cells and differentiation of osteoclasts before adding various concentrations of $\mathrm{Gu}-\mathrm{Sui}-\mathrm{Bu}$. After various time intervals (1 day, 3 days or 7 days), the supernatant was removed and $100 \mu \mathrm{l}$ of MTT solution [3-(4,5-dimethylthiazolyl-2)-2,5-diphenyltetrazolium bromide] (MTT, Sigma catalog no. M2128, Sigma Co., St. Louis, MO, USA; $1 \mathrm{mg} / \mathrm{ml}$ ) was added to each well. The plate was incubated at $37^{\circ} \mathrm{C}$ for $4 \mathrm{~h}$ to allow the formation of formazan crystal. The dark blue crystals were dissolved by acid-isopropanol, then the plate was read on Micro Elisa reader (Emax Science Corp., Sunnyvale, California, USA).

\subsection{Analysis of alkaline phosphatase (ALP), acid phosphatase $(A C P)$ and prostaglandin $E_{2}\left(P G E_{2}\right)$ in culture medium}

ALP and ACP activities released from the cells into the medium were measured with a commercially available assay kit (Procedure no. ALP-10; Procedure no. 435, acid phosphatase, leukocyte, Sigma Co., St. Louis, MO, USA). The production of prostaglandin $\mathrm{E}_{2}$ $\left(\mathrm{PGE}_{2}\right)$ in culture medium was also analyzed with a commercially available assay kit (Cayman Chemical Company, MI, USA). 


\subsection{Analysis of cytoplasmic ALP and ACP}

At the end of the experimental period, ALP and ACP activities were determined following lysis of the cells with the detergent Triton X-100 (Sigma T 8787, Louis, MO, USA; $1 \%$ in Hanks' balanced salt solution, $30 \mathrm{ml}$ at $37^{\circ} \mathrm{C}$ ). Cytoplasmic ALP and ACP values were determined by the methods described for the measurements of culture media.

\subsection{Statistical analysis}

The differences between various samples were evaluated by an analysis of variances statistic method. The post hoc test performed was Bonferroni's $t$ test. The level of statistical significance was defined as $P<0.05$.

\subsection{Northern blot analysis}

For the assay, the rat alveolar mononuclear cellscalvarias osteoblasts co-culture system is the same as that described above, which was incubated in the presence of $1 \mathrm{mg} / \mathrm{ml}$ concentration of Gu-Sui-Bu. After various time intervals, the supernatant was removed, total RNA was isolated from cell cultures using the QIAGEN Rneasy kit in combination with the QiaShredder from QIAGEN (Hilden, Germany). Ten micrograms of total RNA was separated on a $1.5 \%(\mathrm{w} / \mathrm{v})$ agarose/formaldehyde gel using continuous buffer circulation [12] and then transferred to a nylon membrane (Millipore, Bedford, MA, USA) by capillary blotting [13].

In the preparation for osteopontin and osteonectin cDNA probe, the primer pair sequences used were obtained from published sequences and was purchased from MDB, Inc., Taipei, Taiwan. The amplification procedure consisted of 35 cycles (denaturation at $95^{\circ} \mathrm{C}$ for $1 \mathrm{~min}$, annealing at $58^{\circ} \mathrm{C}$ for $1 \mathrm{~min}$, elongation at $72^{\circ} \mathrm{C}$ for $5 \mathrm{~min}$ ) for osteonectin and osteopontin with the oligonucleotide primer as shown in Table 1. These amplified cDNA by PCR was fractionated by electrophoresis in an agarose gel and was visualized by ethidium bromide staining. These amplified products were confirmed by sequencing to be those of the gene transcripts by the detection of an 851 bp band (D28875 Rat mRNA for osteonectin 120-971, Lee et al. [14]), 884 bp band (D1456 Rat mRNA for osteopontin 1461030, Oldberg et al. [15]). Antisense and sense DIG (digoxigenin)-cDNA probes were generated by osteopontin or osteonectin mRNA as templates, respectively [16].

Hybridization was done at $50^{\circ} \mathrm{C}$ for $16 \mathrm{~h}$ in humid chamber and then digested with Rnase. A hybridization solution consisted of $50 \%$ deionized formamide, $10 \%$ dextran sulfate, Denhardt's solution, 4 X SSC, $10 \mathrm{~mm}$ Dithiothreitol, Bakers Yeast t RNA, and $0.6 \mu \mathrm{g} / \mathrm{ml}$ of heat denatured $\left(70^{\circ} \mathrm{C} 5 \mathrm{~min}\right)$ DIG (digoxigenin)-cDNA probe. Detection of DIG-cDNA probe/mRNA hybrid was done using the DIG Nucleic acid detection Kit (Boehringer Mannheirn Inc., Mannheirn, Germany). The kit contained ALP-conjugated anti Digoxigenin antibody, ALP substrates of nitroblue tetrazolium salt (NBT) and X-Phosphate (5-bromo-4-chloro-3-indolyl phosphate toluidinium salt). The procedure was modified from Nomura's method [17,18]. All the experiments were carried out at least three times, and the representative blots are shown.

\subsection{Mature osteoclasts differentiation assay}

Osteoclasts were isolated from long bones of mature Wistar rats using methods described by Chambers et al. [19]. Bones (tibia/fibula/femur) were removed, cleaned of soft tissue and fragmented (by crushing). Bone fragments were then washed extensively and cells collected in culture media consisting of alpha-MEM (Gibco BRL, Rockville, MD, USA) supplemented with $15 \%$ heat-inactivated fetal calf serum (Gibco BRL, Rockville, MD, USA), antibiotics (gentamicin $50 \mu \mathrm{g} / \mathrm{ml}$ [Gibco BRL, Rockville, MD, USA], penicillin G $100 \mu \mathrm{g} /$ $\mathrm{ml}$ [Gibco BRL, Rockville, MD, USA]) and $10^{-8} \mathrm{M} 1,25$ vitamin D3 (1,25 Dihydroxycholecalciferol, Sigma, St. Louis MO, USA). Cells were centrifuged at low speed $(200 \mathrm{~g})$ and this heterogeneous cell population containing osteoclasts was seeded onto culture plates to quantify and characterize the cell populations. Equal amount of cell population obtained from the same rat was seeded on each well. The day of implantation was day zero. One $\mathrm{mg} / \mathrm{ml}$ of Gu-Sui-Bu and control samples were evaluated at day 8 . The medium was changed every 3 days and assay of tartrate-resistant acid phosphatase (TRAP) stain was done at day 8.

Cells in culture were examined for the expression of TRAP according to the method of Minkin [20]. After fixation, the cells were washed three times with PBS and then incubated (for $30 \mathrm{~min}$ ) with AS-BI phosphate (Sigma, St. Louis, MO, USA) as a substrate in Michaelis-Veronal Acetate Buffer at $\mathrm{pH} 5.0$ in the presence of $20 \mathrm{~mm}$ L-tartaric acid (ICN, Montreal, QC, CA) and with hexazonium pararosanilin as a coupling agent. TRAP positive (TRAP + ) cells stained ruby red. Cells that stained positive for TRAP and had three or more nuclei were identified as osteoclasts. For each experiment a minimum of three repeats was done.

\section{Results}

\subsection{Mixed-bone cells and osteoblasts cell population}

Fig. 1 shows the effect of various concentrations of Gu-Sui-Bu on bone cells population measured by MTT 
assay. When mixed-bone cells are cultured with $10 \mathrm{mg} /$ $\mathrm{ml}$ concentrations of $\mathrm{Gu}-\mathrm{Sui}-\mathrm{Bu}$ for $24 \mathrm{~h}$, there is a significant decrease in the mixed-bone cell population, while in the concentration of $1 \mathrm{mg} / \mathrm{ml} \mathrm{Gu}-\mathrm{Sui}-\mathrm{Bu}$, the population of mixed-bone cells increased significantly and this effect persists till the end of 7 days' culture (Fig. 1). When the concentration of Gu-Sui-Bu is $<100 \mu \mathrm{g} / \mathrm{ml}$, the effect of Gu-Sui-Bu on the mixed-bone

Table 1

Oligonucleotide primer for osteonectin and osteopontin

\begin{tabular}{|c|c|}
\hline Osteonectin & $\begin{array}{l}\text { (D28875 rat mRNA for osteonectin 120-971, Lee } \\
\text { et al. [14]) }\end{array}$ \\
\hline $5^{\prime}$ primer & 60 CCCAGCATCATGAGGCCTGGATCTT 85 \\
\hline $3^{\prime} r$ primer & $\begin{array}{l}975 \text { CTTAGATCACCAGATCCTTGTTGATG } \\
950\end{array}$ \\
\hline Osteopontin & $\begin{array}{l}\text { (D28875 rat mRNA for osteonectin 120-971, Lee } \\
\text { et al. [14]) }\end{array}$ \\
\hline $5^{\prime}$ Primer & $\begin{array}{l}75 \text { CAACCATGAGACTGGCAGTGGTTTGC } \\
90\end{array}$ \\
\hline $3^{\prime} r$ Primer & $\begin{array}{l}1042 \text { GCCTCTTCTTTAATTGACCTCAGAAG } \\
1016\end{array}$ \\
\hline
\end{tabular}

cells disappeared. In this study, we selected the concentration of $1 \mathrm{mg} / \mathrm{ml} \mathrm{Gu}-\mathrm{Sui}-\mathrm{Bu}$ for the evaluation of further bone cell activities.

When osteoblasts were cultured with Gu-Sui-Bu for 1 day, the cell population showed significant increase in all the samples $(P<0.01)$ except the highest concentration (i.e. $10 \mathrm{mg} / \mathrm{ml}, P=0.4359$ ). As the interval of culture increases, the effect of increase in osteoblasts population was only observed in the lower concentration. When osteoblasts were cultured with Gu-Sui-Bu for 7 days, the increase in cell population was noted in the samples with the concentration of $10 \mathrm{ng} / \mathrm{ml}(P=0.0348)($ Fig. 1). At the concentration of $1 \mathrm{mg} / \mathrm{ml} \mathrm{Gu}-\mathrm{Sui}-\mathrm{Bu}$, there was a mild increase of cell population of the osteoblasts at the first day's culture $(P=0.0064)$, the effect of increase in cell population disappeared on the 3rd day $(P=0.2400)$ and the 7th day's culture $(P=0.0900)$ (Fig. 1).

\subsection{ALP, ACP and $P G E_{2}$}

For the mixed-bone cells culture, intracellular total ALP synthesis was significantly increased by the
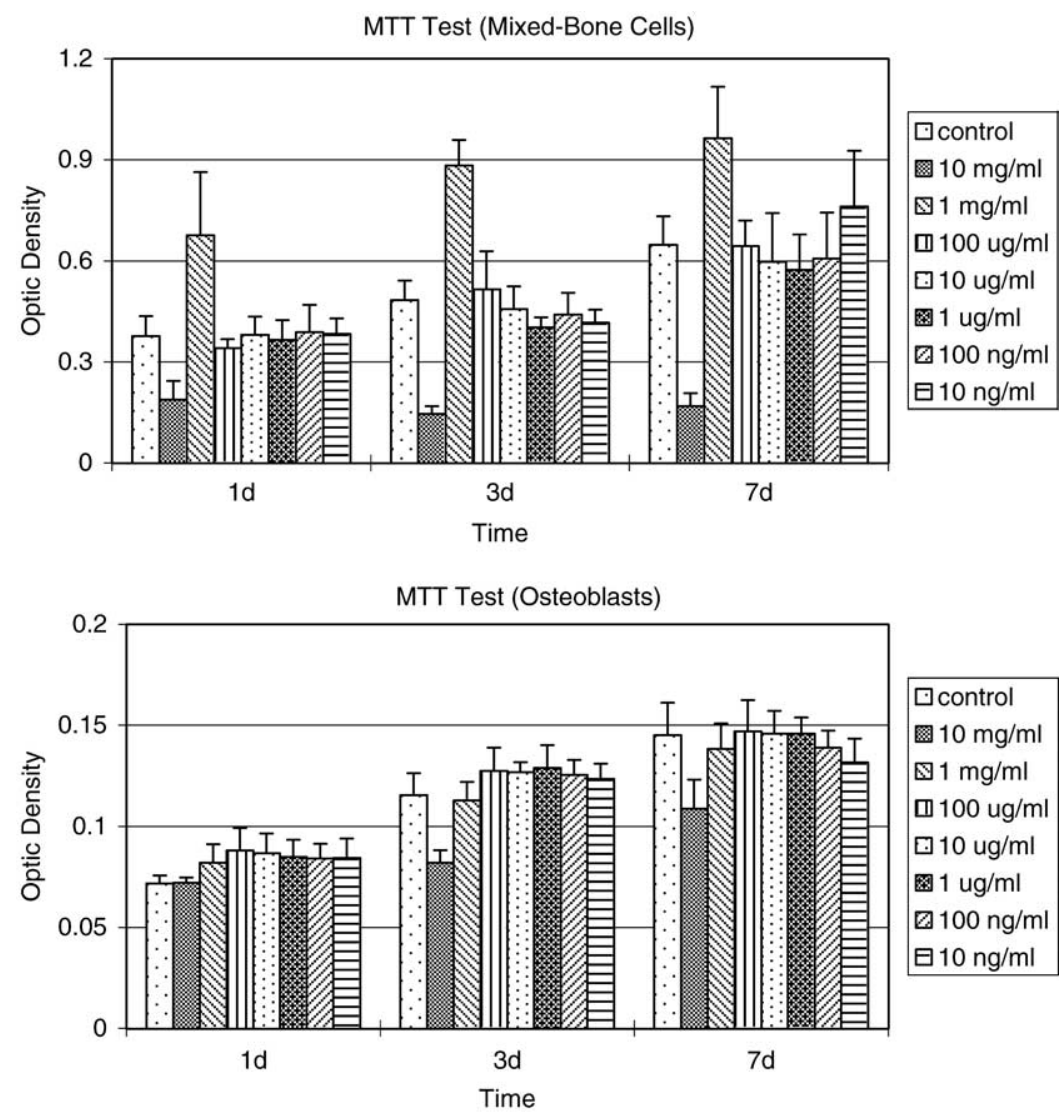

Fig. 1. Changes in the cell population after adding various concentrations of Gu-Sui-Bu into the bone cells or osteoblasts culture $(n=10)$. When mixed-bone cells are cultured with $1 \mathrm{mg} / \mathrm{ml}$ concentrations of Gu-Sui-Bu for $24 \mathrm{~h}$, there is a significant increase in the bone cell population $(P=0.0002)$ and this effect persists till the end of 7 days' culture $(P=0.0001)$. At the concentration of $1 \mathrm{mg} / \mathrm{ml} \mathrm{Gu}-\mathrm{Sui}-\mathrm{Bu}$, there was a mild increase of cell population of the osteoblasts at the first day's culture $(P=0.0064)$, the effect of increase in cell population disappeared at the 3rd day $(P=0.2400)$ and the 7 th day's culture $(P=0.0900)$. (*: $P<0.05 ; * *: P<0.005 ; * * *: P<0.0005)$. 
addition of $1 \mathrm{mg} / \mathrm{ml} \mathrm{Gu}$-Sui-Bu for 7 days $(P<0.005)$, although the total alkaline phosphatase secretion into the medium was decreased, it did not attain a significant level on the 3 day's culture (Fig. 2). When osteoblasts were cultured with $1 \mathrm{mg} / \mathrm{ml} \mathrm{Gu}-\mathrm{Sui}-\mathrm{Bu}$ for 7 days, there was no significant change in ALP titer in the medium, but the intracellular ALP content decreased significantly at the 1st day of culture, while it increased significantly at the 3rd and 7th days' culture (Fig. 2). After adding $1 \mathrm{mg} / \mathrm{ml}$ of Gu-Sui-Bu into mixed-bone cells culture, the ACP amount in culture medium was significantly increased during the 7 days' experimental period $(P<0.0005)$; while the intracellular ACP amount was significantly increased in 1 day and 7 days' culture $(P<0.05)$ (Fig. 3).

After adding $1 \mathrm{mg} / \mathrm{ml}$ of $\mathrm{Gu}-\mathrm{Sui}-\mathrm{Bu}$ to the mixedbone cells culture for 1 day, the concentration of $\mathrm{PGE}_{2}$ in the culture medium significantly increased
$(P=0.0010)$ (Fig. 4). The effect on $\mathrm{PGE}_{2}$ was increased persistently and it reached 25.9 times that of the control medium on the 7th day's culture $(P<0.0005)$ (Fig. 4$)$.

\subsection{Northern blot of osteopontin and osteonectin $m R N A$}

In Northern blot analysis of the control samples, the response of mRNA expression of osteopontin was quite evident at $3 \mathrm{~h}$ ' culture and then decreased gradually during the 7 days' culture; while the osteonectin mRNA expression was quite evident at $3 \mathrm{~h}$ ' culture and the expression persisted till the end of 7 days' culture (Fig. 5). After adding Gu-Sui-Bu into the bone cells culture, the expression of both osteopontin and osteonectin mRNA was down regulated. At the end of 7 days' culture of bone cells with Gu-Sui-Bu, the expression of osteonectin was still faintly observed, but the expression of osteopontin was nearly totally depressed (Fig. 5).
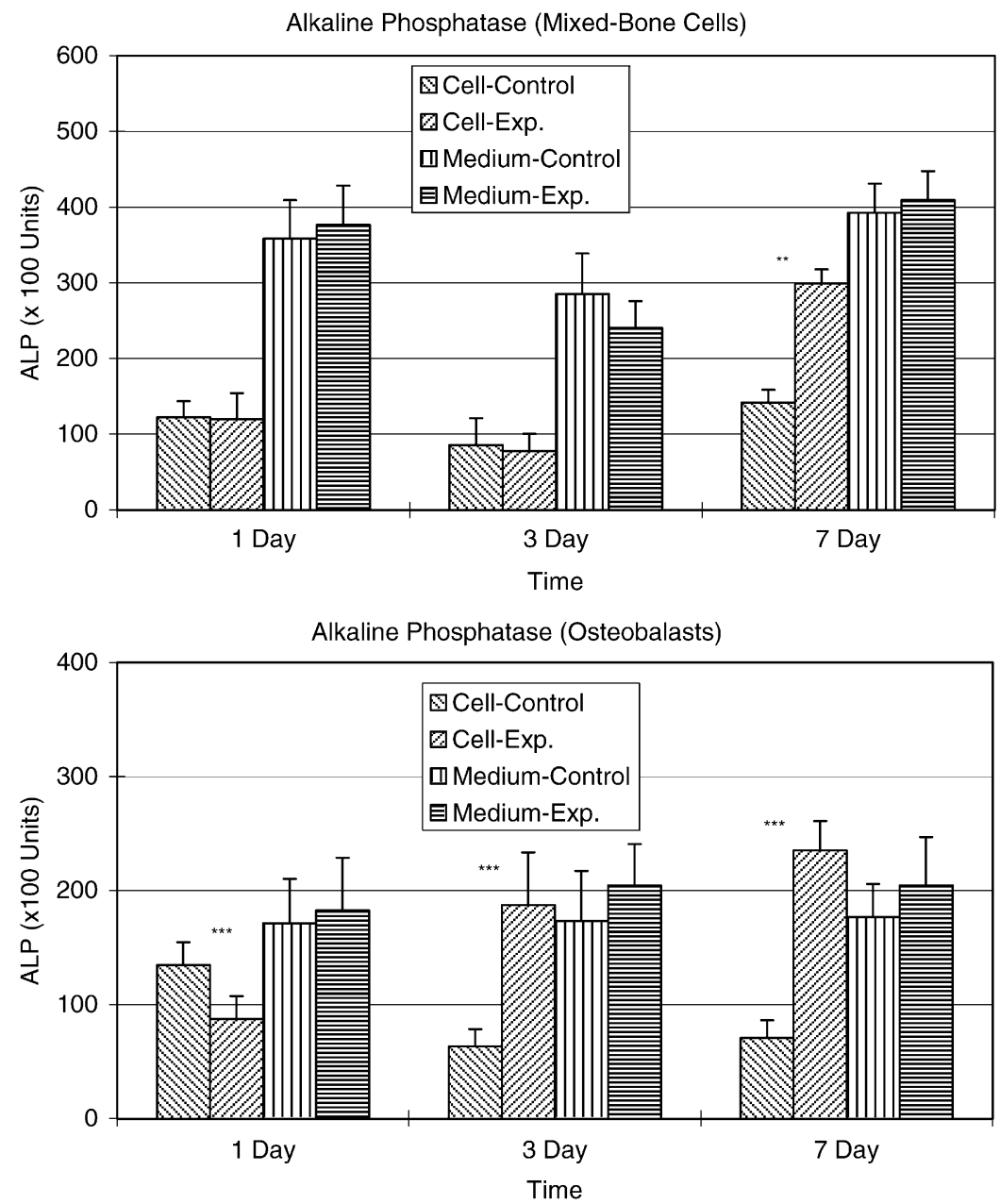

Fig. 2. Changes in total alkaline phosphatase (ALP) titer after adding $1 \mathrm{mg} / \mathrm{ml} \mathrm{Gu-Sui-Bu} \mathrm{into} \mathrm{the} \mathrm{bone} \mathrm{cells} \mathrm{culture}(n=10)$. Alkaline phosphatase (ALP) amount in culture medium did not show any significant change by adding $1 \mathrm{mg} / \mathrm{ml} \mathrm{Gu}$-Sui-Bu for 7 days' culture $(P>0.05)$. Intracellular ALP synthesis is significantly increased by the addition of $1 \mathrm{mg} / \mathrm{ml} \mathrm{Gu}$-Sui-Bu for 7 days $(P<0.05)$. When osteoblasts were cultured with $1 \mathrm{mg} / \mathrm{ml} \mathrm{Gu}$-SuiBu for 7 days, the intracellular ALP content was initially decreased at the 1st day of culture, then increased significantly at the 3rd and 7th days' culture. (*: $P<0.05$; **: $P<0.005$; ***: $P<0.0005)$. 


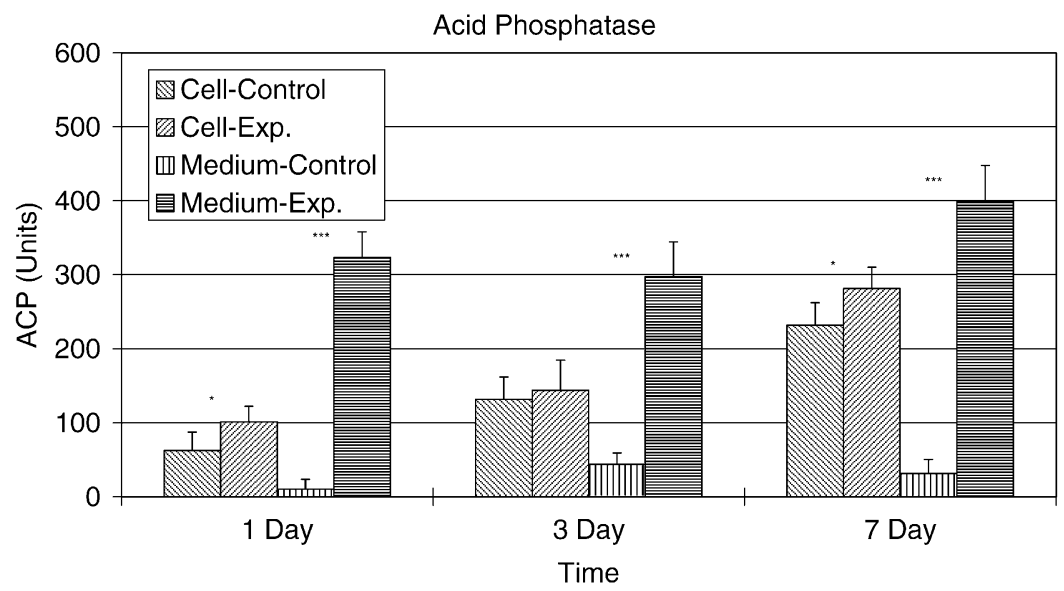

Fig. 3. Changes in total acid phosphatase (ACP) titer after adding $1 \mathrm{mg} / \mathrm{ml} \mathrm{Gu}$-Sui-Bu into the bone cells culture $(n=10)$. After adding $1 \mathrm{mg} / \mathrm{ml}$ of Gu-Sui-Bu into bone cells culture, both the intracellular ACP titer and the ACP amount in culture medium were significantly increased $(P<0.05)$. (*: $P<0.05 ; * *: P<0.005 ; * * *: P<0.0005)$.

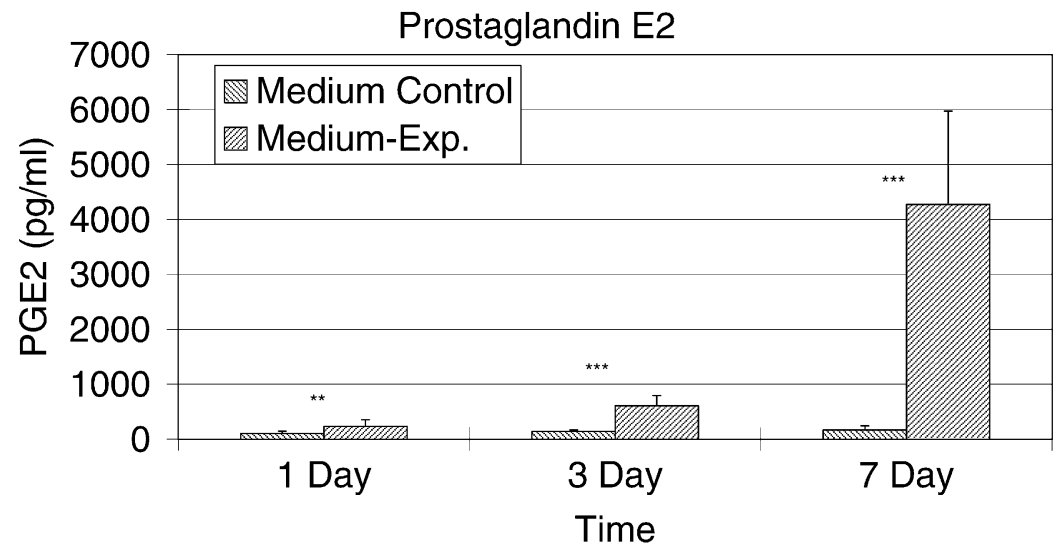

Fig. 4. Changes in prostaglandin $\mathrm{E}_{2}\left(\mathrm{PGE}_{2}\right)$ titer after adding $1 \mathrm{mg} / \mathrm{ml} \mathrm{Gu}$-Sui-Bu into the bone cells culture $(n=10)$. After adding $1 \mathrm{mg} / \mathrm{ml}$ of $\mathrm{Gu}-$ Sui-Bu into bone cell culture, the $\mathrm{PGE}_{2}$ titer in culture medium was significantly increased $(P<0.05)$. The effect on the PGE 2 was increased persistently and reached 25.9 times that of the control medium at the 7 th day's culture. (*: $P<0.05 ; * *: P<0.005 ; * * *: P<0.0005$ ).

\subsection{Osteoclasts differentiation}

In the control group, there were numerous TRAP $(+)$ giant cells visible throughout the whole well. In the concentration of $1 \mathrm{mg} / \mathrm{ml} \mathrm{Gu}-\mathrm{Sui}-\mathrm{Bu}$, the formation of multi-nucleated osteoclasts was more active than that of the control group (magnification in the inset); but the average size of the osteoblasts cells is smaller, and no giant cells (nucleus $>20$ ) can be seen (Fig. 6).

\section{Discussion}

There are several reports that demonstrated an improvement in clinical association with the use of traditional Chinese medicines in the treatment of fractures [21]. The traditional Chinese medicines, GuSui- $\mathrm{Bu}$ had been alleged to have therapeutic effects on bone healing [8]. Despite encouraging preliminary reports, basic science and clinical mechanism responsible for this effect have not been identified. This study sought to establish the relationships between bone cells and this specific Chinese medicine Gu-Sui-Bu, which may contribute to the possible justification for the clinical application in the treatment of bone disease.

In a study for evaluation of the cytotoxic and antioxidant effects of the water extract of Gu-sui-Bu, $\mathrm{Liu}$ et al. found that Gu-Sui-Bu was not only noncytotoxic but also has an anti-oxidative effect on osteoblasts [9]. In this study, we found that the addition of $\mathrm{Gu}-\mathrm{Sui}-\mathrm{Bu}$ into the culture medium will significantly affect the cell population of the mixed-bone cells and osteoblasts. Gu-Sui-Bu at $10 \mathrm{mg} / \mathrm{ml}$ reduced the cell population in both osteoblasts and mixed-bone cells at all the time intervals; while $\mathrm{Gu}-\mathrm{Sui}-\mathrm{Bu}$ at $1 \mathrm{mg} / \mathrm{ml}$ did not affect the cell population of rat osteoblasts and the 


\section{$3 \mathrm{hr} 3 \mathrm{hr} \quad 1 \mathrm{~d} \quad 1 \mathrm{~d} \quad 3 \mathrm{~d} \quad 3 \mathrm{~d} \quad 7 \mathrm{~d} \quad 7 \mathrm{~d}$ M Cont. Exp. Cont. Exp. Cont. Exp. Cont. Exp.}

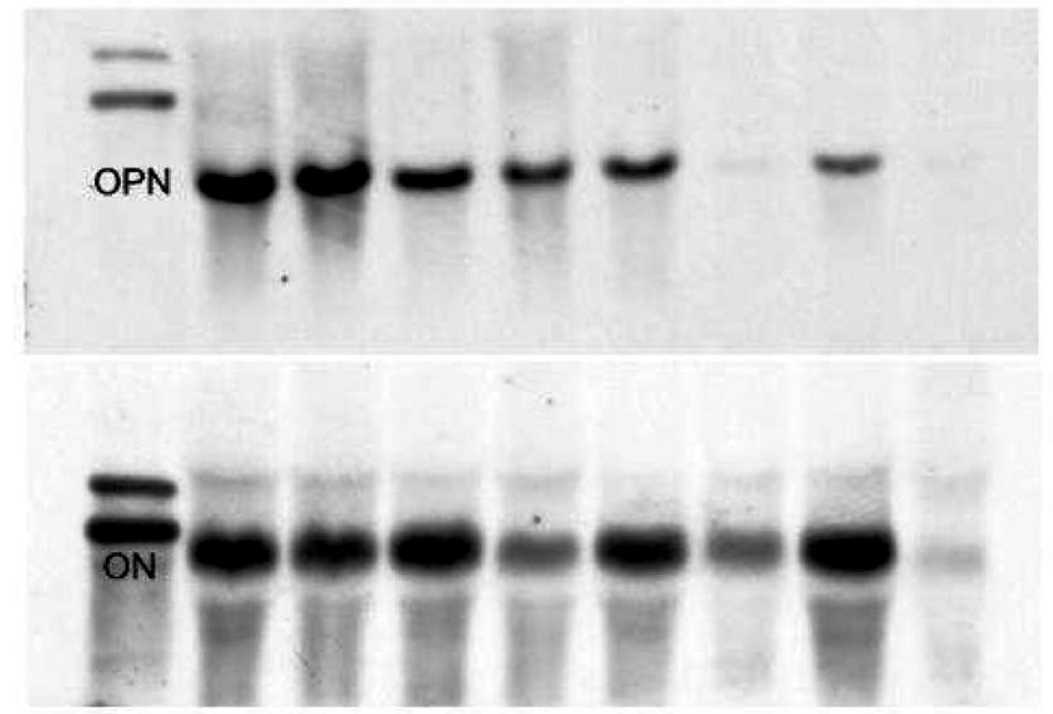

Fig. 5. Northern blotting of osteopontin and osteonectin mRNA expression. In Northern blot analysis of the control samples, the response gene mRNA expression of osteopontin was quite evident at $3 \mathrm{~h}$ culture and then decreased gradually during the 7 days' culture; while the osteonectin mRNA expression was quite evident at $3 \mathrm{~h}$ culture and the expression persisted till the end of 7 days' culture. After adding Gu-Sui-Bu into the bone cells culture, the expression of both osteopontin and osteonectin mRNA were down regulated. At the end of 7 days' culture of bone cells with Gu$\mathrm{Sui}-\mathrm{Bu}$, the expression of osteonectin was still faintly observed, but the expression of osteopontin was nearly totally depressed.
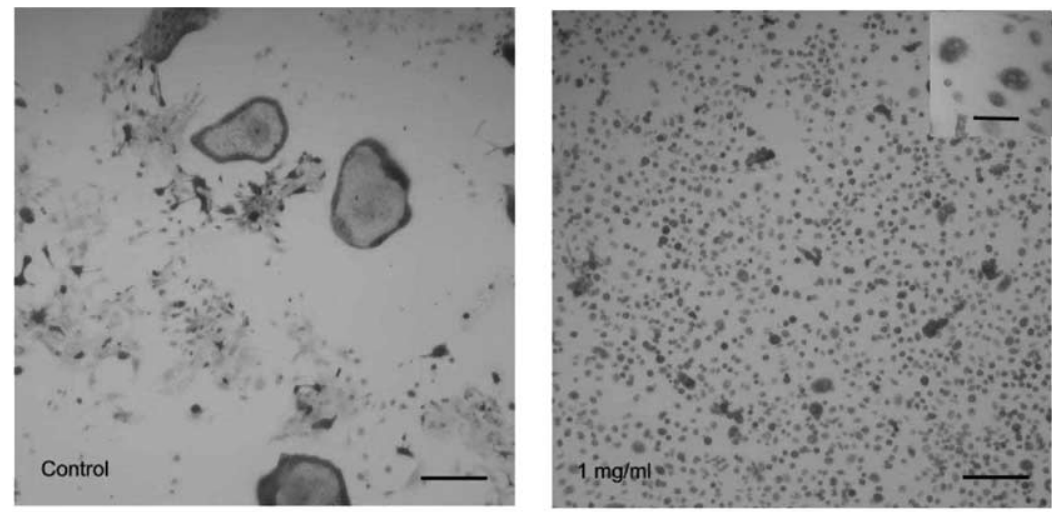

Bar $=200$ um

Bar (Insert) $=100$ um

Fig. 6. Tartrate-resistant acid phosphatase stain of mature osteoclasts culture. In the control group, there were numerous TRAP(+) giant cells visible throughout the whole well. In the concentration of $1 \mathrm{mg} / \mathrm{ml} \mathrm{Gu}$-Sui-Bu, the formation of multi-nucleated osteoclasts was more active than that of the control group (inset); but the average size of the osteoblasts cells is smaller, and no giant cells (nucleus $>20$ ) can be seen. (TRAP stain; Bar $=200 \mu \mathrm{m}$; Bar in the inset $=100 \mu \mathrm{m})$.

mixed-bone cells population increased significantly $(P<0.005)$. When the concentration of Gu-Sui-Bu is $<100 \mu \mathrm{g} / \mathrm{ml}$, the effect of Gu-Sui-Bu on the mixed-bone cells disappeared (Fig. 1). In this study, we selected the concentration of $1 \mathrm{mg} / \mathrm{ml} \mathrm{Gu-Sui-Bu}$ for the further mixed-bone cell activity evaluation.

When osteoblasts were cultured with $1 \mathrm{mg} / \mathrm{ml} \mathrm{Gu}$-Sui$\mathrm{Bu}$, the intracellular ALP decreased significantly at the 1st day's culture; while in the mixed-bone cells culture, there was a slight decrease in both the intracellular ALP and ALP secreted into the medium at the 3rd day's culture (Fig. 2). It seemed that the addition of Gu-Sui$\mathrm{Bu}$ had some inhibitory effect on the bone cells culture in the initial stage. In the mixed-bone cells culture, intracellular ALP content increased significantly at the 7 th day's culture $(P<0.005)$; while in the osteoblasts cell 
culture, intracellular ALP content increased significantly at the 3rd and 7th day's culture $(P<0.0005)$ (Fig. 2). This fact combined with the stationary results of osteoblasts cell population probably imply the fact that $\mathrm{Gu}-\mathrm{Sui}-\mathrm{Bu}$ can increase the intracellular synthesis of ALP by the osteoblasts.

Prostaglandins (PGs) are potent modulators of bone metabolism and ubiquitous local hormones that have been previously reported to exert important effects on the skeleton. In recent years, observations in human [22] and animal studies have shown that PGs (in particular $\left.\mathrm{PGE}_{2}\right)$ are powerful anabolic agents for long bones in rats when administered systemically [23,24]. In the current study, the concentration of $\mathrm{PGE}_{2}$ in the culture medium significantly increased after Gu-Sui-Bu administration (Fig. 4). The effect on the $\mathrm{PGE}_{2}$ was even more marked and reached $4272.14 \mathrm{pg} / \mathrm{ml}$ at the 7 th day's culture, which was 25.9 times of the control medium $(164.83 \mathrm{pg} / \mathrm{ml})$ (Fig. 4). Our results demonstrate that administration of Gu-Sui-Bu can accelerate the speed of intracellular ALP synthesis and extracellular secretion of $\mathrm{PGE}_{2}$ into the medium by the bone cells. As mentioned by Chenu et al., $\mathrm{PGE}_{2}$ is a potent inhibitor of multinucleate-osteoclasts cell formation [25]. Further studies about the effect of Gu-Sui-Bu on the osteoclasts were performed.

A major feature of bone is its continuous remodeling. The molecular constituents of bone are closely related to this process. To clarify the possible mechanism of GuSui- $\mathrm{Bu}$ on the bone cell activities, studies about the expression of bone cell molecular constituents were performed. Osteopontin is thought to promote or regulate the adhesion, attachment, and spreading of osteoclasts to the bone surface during bone resorption $[26,27]$. It is known to be produced by osteoblasts [28$30]$, as well as osteoclasts $[29,31,32]$. Osteopontin can be dephosphorylated by the extracellular tartrate-resistant acid phosphatase [33]; such dephosphorylated osteopontin is then unable to promote in vitro binding of osteoclasts [34]. Another protein abundant in bone with potential roles in regulating cellular activities, albeit not in binding the cells, is osteonectin [35]. Studies in vitro have shown the roles of osteonectin in modulating cell division and cell migration [35] and perhaps initiating active mineralization in normal skeletal tissue [36].

After the addition of $\mathrm{Gu}-\mathrm{Sui}-\mathrm{Bu}$ into bone cell culture, both the intracellular ACP amount and the ACP in culture medium were significantly increased during the experimental period (Fig. 3). As noted above, increased ACP content in culture medium will dephosphorylate the osteopontin and subsequently decrease the capability of osteoclasts adhesion and increase the capability of osteoclasts migration. The osteopontin and osteonectin mRNA expression was significantly down regulated in the bone cells cultured with $\mathrm{Gu}-\mathrm{Sui}-\mathrm{Bu}$ (Fig. 5). The increased intracellular ALP, ACP synthesis and extracellular secretion of $\mathrm{PGE}_{2}$ into medium by the bone cells after administration of Gu-Sui-Bu and the decrease in osteopontin and osteonectin mRNA expression denote that this environment is more suitable for osteoclasts migration and early differentiation of osteblasts, but is not quite favorable for the mineralization of the osteoblasts. This environment is likely to be present in the early stage of the fracture healing. This result is further supported by the histological examination that the formation of smaller multinucleated osteoclasts, and not the TRAP $(+)$ giant cells, was greatly increased (Fig. 6).

Chinese biomedical scientists are now developing a new approach to medicine by combining traditional Chinese medicine and western biomedical science. Despite encouraging preliminary clinical reports about clinical improvement with the use of traditional Chinese medicines, Gu-Sui-Bu, basic science and clinical mechanism responsible for this effect has not yet been identified. In this study, we demonstrated that Gu-Sui$\mathrm{Bu}$ [Drynaria fortunei (Kunze) J. Sm.] has potential effects on the bone cells culture. One of the major effects of $\mathrm{Gu}-\mathrm{Sui}-\mathrm{Bu}$ on the bone cells is probably mediated by its effect on the osteclasts attachment. Although our study had limitations and our findings are preliminary, continued and advanced study on the alterations in gene expression of bone cells by Chinese medicines will provide a basis for understanding the observed bone cell responses to various pharmacological interventions.

\section{Acknowledgements}

The authors sincerely thank the National Health Research Institutes (ROC) for their financial support of this research.

\section{References}

[1] Cheng JT. Drug therapy in Chinese traditional medicine. J Clin Pharmacol 2000;40:445-50.

[2] Koh HL, Woo SO. Chinese proprietary medicine in Singapore: regulatory control of toxic heavy metals and undeclared drugs. Drug Saf 2000;23:351-62.

[3] Chan K. Progress in traditional Chinese medicine. Trends Pharmacol Sci 1995;16:182-7.

[4] Yuan R, Lin Y. Traditional Chinese medicine: an approach to scientific proof and clinical validation. Pharmacol Ther 2000;86:191-8.

[5] Arnold MD, Thornbrough LM. Treatment of musculoskeletal pain with traditional Chinese herbal medicine. Phys Med Rehabil Clin N Am 1999;10:663-71.

[6] Friedrich MJ. Chinese and US health care leaders discuss challenges of the 21st century. J Amer Med Assoc 2001;8(286):659-61.

[7] Lee KH. Research and future trends in the pharmaceutical development of medicinal herbs from Chinese medicine. Public Health Nutr 2000;3:515-22. 
[8] Ma KC, Zhu TY, Wang FX. Stimulative effects of gusuibu (Drynaria baronii) injection on chick embryo bone primordium calcification in vitro. Am J Chin Med 1996;24:77-82.

[9] Liu HC, Chen RM, Jian WC, Lin YL. Cytotoxic and antioxidant effects of the water extract of the traditional Chinese herb gusuibu (Drynaria fortunei) on rat osteoblasts. J Formos Med Assoc 2001;100:383-8.

[10] Sun JS, Chang WHS, Hong RC, Hung TY, Lin FH, Liu HC. Alveolar mononuclear cells can develop into multinucleated osteoclasts: an in vitro cell culture model. J Biomed Mater Res 2000;52:142-7.

[11] Mosmann T. Rapid colorimetric assay for cellular growth and survival: application to proliferation and cytotoxicity assay. $\mathbf{J}$ Immunol Meth 1983;65:55-63.

[12] Lehrach H, Diamond D, Wozney JM, Boedtker H. RNA molecular weight determinations by gel electrophoresis under denaturing conditions, a critical reexamination. Biochemistry 1977; 16:4743-51.

[13] Thomas PS. Hybridization of denatured RNA and small DNA fragments transferred to nitrocellulose. Proc Natl Acad Sci USA 1980;77:5201-5.

[14] Lee MJ, Saijoh K, Nestler EJ, Duman RS, Sumino K. Regional differences in expression of osteonectin mRNA after administration of calcium to rats. Unpublished (full staff reviewed) 1995.

[15] Oldberg A, Franzen A, Heinegard D. Cloning and sequence analysis of rat bone sialoprotein (osteopontin) cDNA reveals an Arg-Gly-Asp cell binding sequence. Proc Natl Acad USA 1986;83:8819-23.

[16] Dohi Y, Ohgushi H, Tabata S, Yoshikawa T, Dohi K, Moriyama $\mathrm{T}$. Osteogenesis associated with bone gla protein gene expression in diffusion chambers by bone marrow cells with demineralized bone matrix. J Bone Miner Res 1992;7:1173-80.

[17] Nomura S, Wills AJ, Edwards DR, Heath JK, Hogan BL. Developmental expression of 2ar (osteopontin) and SPARC (osteonectin) RNA as revealed by in situ hybridization. J Cell Biol 1988;6:441-50.

[18] Hirota S, Takaoka K, Hashimoto J, Nakase T, Takemura T, Morii E, Fukuyama A, Morihana K, Kitamura Y, Nomura S. Expression of mRNA of murine bone-related proteins in ectopic bone induced by murine bone morphogenetic protein- 4 . Cell Tissue Res 1994;277:27-32.

[19] Chambers TJ, Revell PA, Fuller K. Athanasou nA: resorption of bone by isolated rabbit osteoclasts. J Cell Science 1984;66:383-99.

[20] Minkin C. Bone acid phosphatase: tartrate resistant acid phosphatase as a marker of osteoclast function. Calcif Tissue Int 1982;34:285-90.

[21] Huang HF, You JS. The use of Chinese herbal medicine on experimental fracture healing. Am J Chin Med 1997;25:351-6.

[22] Jorgensen HR, Svanholm H, Host A. Bone formation induced in an infant by systemic prostaglandin-E2 administration. Acta Orthop Scand 1988;59:464-6.
[23] Ito H, Ke HZ, Jee WS, Sakou T. Anabolic responses of an adult cancellous bone site to prostaglandin E2 in the rat. Bone Mineral 1993;21:219-36.

[24] Akamine T, Jee WS, Ke HZ, Li XJ, Lin BY. Prostaglandin E2 prevents bone loss and adds extra bone to immobilized distal femoral metaphysis in female rats. Bone 1992;13:11-22.

[25] Chenu C, Kurihara N, Mundy, Roodman GD. Prostaglandin E2 inhibits formation of osteoclast like cells in long-term human marrow cultures but is not a mediator of the inhibitory effects of transforming growth factor beta. J Bone Miner Res 1990; 5:677-81.

[26] Reinholt FP, Hultenby K, Oldberg A, Heinegard D. Osteopontin - a possible anchor of osteoclasts to bone. Proc Natl Acad Sci USA 1990;87:4473-5.

[27] Ikeda T, Nomura S, Yamaguchi A, Suda T, Yoshiki S. In situ hybridization of bone matrix proteins in undecalcified adult rat bone sections. J Histochem Cytochem 1992;40:1079-88.

[28] Weinreb M, Shinar D, Rodan GA. Different pattern of alkaline phosphatase, osteopontin, and osteocalcin expression in developing rat bone visualized by in situ hybridization. J Bone Miner Res 1990;5:831-42.

[29] Merry K, Dodds R, Littlewood A, Gowen M. Expression of osteopontin mRNA by osteoclasts and osteoblasts in modelling adult human bone. J Cell Sci 1993;104:1013-20.

[30] Hirakawa K, Hirota S, Ikeda T, Yamaguchi A, Takemura T, Nagoshi J, Yoshiki S, Suda T, Kitamura Y, Nomura S. Localization of the mRNA for bone matrix proteins during fracture healing as determined by in situ hybridization. J Bone Mineral Res 1994;9:1551-7.

[31] Tezuka K, Sato T, Kamioka H, Nijweide PJ, Tanaka K, Matsuo T, Ohta M, Kurihara N, Hakeda Y, Kumegawa M. Identification of osteopontin in isolated rabbit osteoclasts. Biochem Biophy Res Commun 1992;186:911-7.

[32] Dodds RA, Ali N, Pead MJ, Lanyon LE. Early loading-related changes in the activity of glucose 6-phosphate dehydrogenase and alkaline phosphatase in osteocytes and periosteal osteoblasts in rat fibulae in vivo. J Bone Miner Res 1993;8:261-7.

[33] Reinholt FP, Widholm SM, Ek-Rylander B, Andersson G. Ultrastructural localization of a tartrate-resistant acid ATPase in bone. J Bone Miner Res 1990;5:1055-61.

[34] Ek-Rylander B, Flores M, Wendel M, Heinegard D, Andersson G. Dephosphorylation of osteopontin and bone sialoprotein by osteoclastic tartrate-resistant acid phosphatase Modulation of osteoclast adhesion in vitro. $\mathrm{J}$ Biol Chem 1994;269:14853-6.

[35] Lane TF, Sage EH. The biology of SPARC, a protein that modulates cell-matrix interactions. FASEB J 1994;8:163-73.

[36] Termine JD, Kleinman HK, Whitson SW, Conn KM, McGarvey ML, Martin GR. Osteonectin, a bone-specific protein linking mineral to collagen. Cell 1981;26:99-105. 